\title{
Didactic Options and Experience with 3D Printing Technology and Lego Mindstorms Kits
}

\author{
Igor ČERNÁK, Michal ROJČEK, Patrik SITIARIK
}

\begin{abstract}
The article discusses didactic possibilities and experiences with the use of $3 \mathrm{~d}$ printing technology and Lego Mindstorms. 3d printing we use to teach computer graphics. It is essential that the teacher has a knowledge of how technology works and how it can implement it into teaching. The same is true of the Lego Mindstorms, which we use to teach programming and robotics. The article focuses on both technologies in terms of their capabilities and practical experience in teaching information subjects.
\end{abstract}

Keywords: 3D printing, Lego Mindstorms, RepRap, Robotics, Programming.

\section{Introduction}

Today time is marked by consumism and this is also true in the realm of education. Students are taught more to receive content (consume it) than to create it. It's hard to take them because they've already watched thousands of websites and videos, and they're hard to surprise or amaze. The way it could be changed is to teach students that even they can create something. Show them the potential of their own creativity, imagination or artistic creation. Involve not only the head, but also the hands. Teach them to think and create. Look at things in a comprehensive perspective. Analyze and systematize. Use new options to do this. Some of them like 3D printing and Lego Mindstorms kits will be presented in the following chapters.

\section{3D Printing}

3D printing is a phenomenon that has been greatly spread over recent years to schools, households and small businesses, especially since 3D printers have become affordable for these groups of users as well. In 2007, RepRap was given a project of a self-closing printer, which apparently had little contribution to the massive expansion of this technology. RepRap is an international community project of 3D printers developed on the principle of open hardware. The RepRap 3D printer is composed predominantly of many plastic parts that can be printed on another RepRap printer. The name RepRap is the abbreviation of Replicating Rapid Prototyper, which means that it is capable of self-replication and rapid prototyping. The entire documentation needed to compile the hardware and the operation of its own RepRap, including firmware and control software, is released under the GNU (General Public License) license, under which free software is issued [1, 2]. Thanks to its overall openness and affordability, RepRap has become a very popular project for the worldwide community of domestic champions. In some mail stores it is possible to buy all the parts on RepRap at favorable prices. A simple 3D printer can be bought already in order for a few dozen euros. Not only the open hardware community but also established companies that deal with the development and sale of professional 3D printers offer cheap models for home use.

Central-European Journal of New Technologies in Research, Education and Practice

Volume 2, Number 1, 2020. 


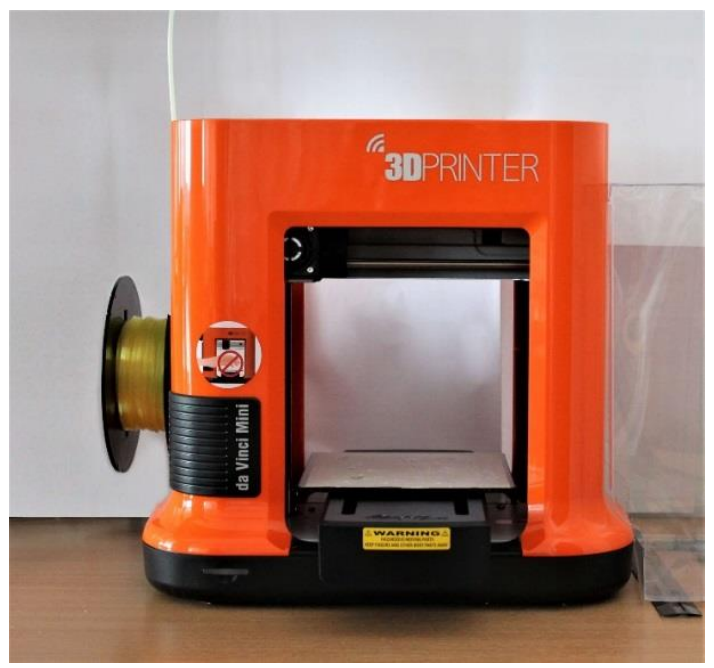

Figure 1: 3D printer XYZ da Vinci Mini w

The affordability of this technology opens up new possibilities in teaching in the development of information and technological thinking, and the artistic sentiment of pupils and students. It provides a platform through which pupils and students can make their ideas more tangible. They have a choice of different software tools for designing 3D models that are free. From simpler tools designed for children and beginners e.g. Tinkercad [3], to more complex, designed for advanced and professionals e.g. FreeCAD [4] - parametric modeling, or Blender [5] for general 3D graphics. All changed tools can export 3D objects to the STL (stereolithography) format, which is suitable for $3 \mathrm{D}$ printers.

Students learn to move around in 3D space when creating a 3D model. They detect that the object should be viewed from multiple pages for editing. They learn what is a trait, bokorys, floor plan, orthographic and Perspective view. Basic graphic transformations such as shift, rotate, and scale change. They learn a variety of modelling techniques, such as parametric modelling, modelling based on the application of the Boolean operation of the association and the difference, or their combination. For parametrical Modelling, you specify the object's exact numeric parameters such as height, width, depth, number of polygons, rotation angle, magnification percentage, etc. When modeled using Boolean, the unification operation creates new objects by pooling multiple bodies into a single body. In the operation of the Booleovský difference, they "cut off" from the solids using other bodies. The TINKERCAD environment is also handled by children of first instance. They can draw their own toy and print them on a 3D printer with the help of the teacher. Is there more motivation for children than this?

If the teacher wants to reach for the finished 3D models, they are available in large databases. For all I think very popular www.thingiverse.com, where $3 \mathrm{~d}$ models are of different types or specialized Database of technical 3d models www.grabcad.com, or search engine 3D models www.yeggi.com, which looks for $3 \mathrm{~d}$ models in multiple databases at once.

If the object is difficult to modeling, and in the 3D model databases (a typical example can be a human head of a particular person), it remains only to purchase or produce a 3D scanner that can be scanned by the object. From affordable models there is not so much choice. In this case, we recommend that you focus on quality software because it depends on how the missing pixels will be counted. Most of these scanners leave the scanned 3D models of holes, which must subsequently be "implicate".

Central-European Journal of New Technologies in Research, Education and Practice

Volume 2, Number 1, 2020. 
If you already have pupils, whether students prepared a 3D model, followed by the phase of 3D printing. Here we recommend to clearly use the wholesome printing material (filament) of the PLA (PolyLactic Acid) plastic. This plastic is characterized by the fact that when the press is not lit, it does not release the harmful fumes when heated and is wholesome. In addition, the 3D printer may not have a heated washer as in ABS plaste. To snap a model, just stick glue (you need to try more brands). The printing process is time-consuming, so you need to schedule your lessons to print your model every time. For example, at the end of the lesson you can print models (preferably more at once), depending on the size of the print space and the size of the models. We recommend that you introduce restrictions on the size of the object due to the parallelism of the printing, but also the consumption of the print filament. Then pupils and students can take home their product and boast to their parents or friends with their creations.

With us at the Department of Informatics PF KU in Ružomberok, we use 3D printer and 3D scanner especially in the subject of computer graphics, where we teach different methods of 3D modeling. 3D printing can also be used in other subjects: for example, computer system architectures or the basics of electrotechnics for informatics, where we use the Arduino electronic kits. Just 3D Printing and Arduino (or other type of microcontroller) can be used to design and produce more complex mechatronic constructions and equipment see. Figure. 2. In the last time, we have dealt with the production of robotic hands in the department of EEZYbotArm MK3, which consists of 21 plastic parts, which we pushed approx. 5 working days. Electronics form the Arduino microcontroller with a four-axis stepper motor driver, 3 Step Motors and one servo motor to handle. The Model implements reverse kinematics.

Another model is Otto robot, which can be variously modified, skinned and programmed eg. in child prog. language Scratch. It consists of six plastic parts and electronics formed again by the Arduino microcontroller, USG sensor, 4 micro servos, piezo buzzer, bluetooth module and other optional components. The Robot can be used as a didactic hint for Scratch.

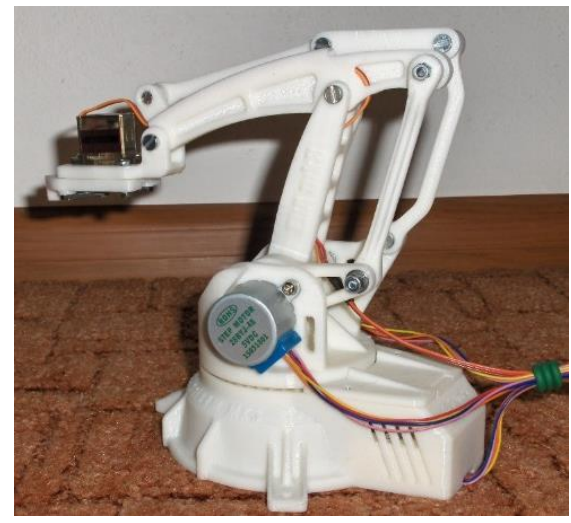

a) Robotical hand EezybotArm MK3

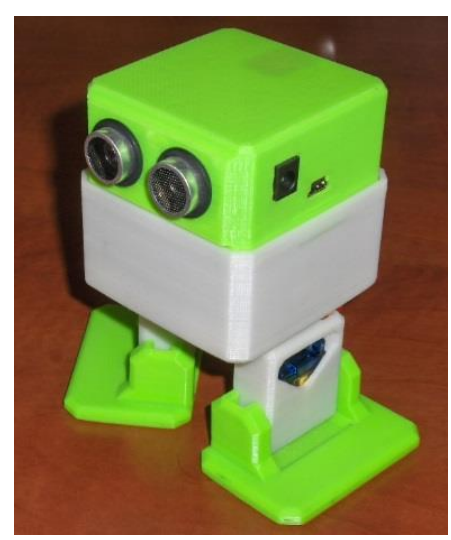

b) OTTO educational robot

Figure 2: Combining 3d printing and electronics.

The products we did in the Department of Informatics PF KU in Ružomberok.

Both models can be found on the page www.thingiverse.com, where they can be downloaded freely. The Open hardware platform is very promising and monetization of this platform is acceptable [6].

Another prospective platform is the Lego Mindstorms kit, which will be presented in the next chapter.

Central-European Journal of New Technologies in Research, Education and Practice

Volume 2, Number 1, 2020. 


\section{Lego Mindstorms kids}

Robotics and cybernetics are often mentioned terms in professional articles and scientific publications. These terms bind with the automation of the activity that was previously performed manually. The process of automation thus leads to greater efficiency and productivity. Recently, however, the field of robotics is increasingly emerging on the campus of universities and secondary schools.

The area of robotics and automation is also expanding into education, especially on the grounds that the robot can cause attention and interest to the pupil. Increased attention and interest also results in increased motivation to work and learn something new. Lego Mindstorms are an excellent means of first familiarise pupils in pre-school age with the world of robotics. These kits are used not only in high schools but also in secondary schools. There are even common cases where children first become acquainted with this building at elementary School [8].

The Lego Mindstorms kit features a classic Lego cube, a microcontroller module that is also a basic control unit, motors and sensors. History indicates 3 base types of these cubes microcontroller. RCX, NXT 2.0 and EV3. Currently, for the purposes of studies, other uses are mainly used by NXT 2.0 and EV3 microcontrollers.

Microcontrollers NXT and EV3, i.e. the latest generation of these smart cubes are sold together with the Lego kits. In the kit with NXT 2.0 we can find 3 Step Motors, 4 sensors and the Lego parts themselves. The basic sensors that are supplied to the kits are touch, light, acoustic and ultrasonic sensors. Each of these sensors performs different tasks. The touch sensor responds to pressure; This means that when you press it, it performs a task according to which it is programmed. Depending on the program, we can, for example, control the motor movement, react to any other sensor or many other instructions by pressing the sensor. The light sensor recognizes colors and can react to changing lightness also. Again, as in the previous case, it can be used to interact differently with engines or other sensors. The last two sensors that we can find in such a kit are sound and ultrasonic sensors. The audio sensor responds to the sound that is in the vicinity and, depending on it, performs functions by program. The ultrasonic sensor is specific in that it can measure distance and, accordingly, at certain defined values of this distance, change its characteristics of the movement or running of the programme [11], [12].

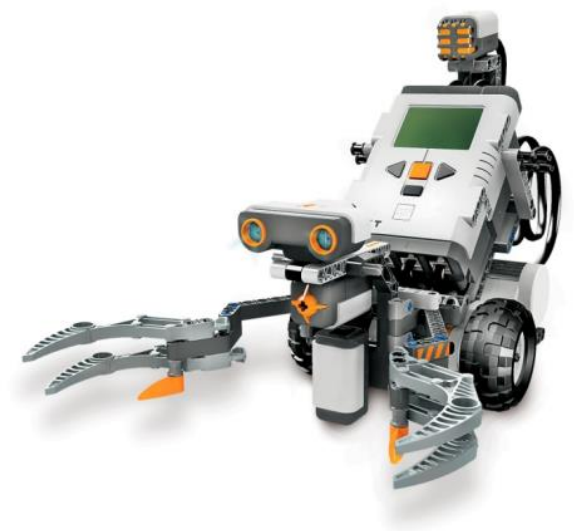

Figure 3: The NXT Robot Model [17]

For developers and those sensors that are not enough, there is a possibility to purchase various additional sensors such as accelerometer, compass or RFID sensor.

Central-European Journal of New Technologies in Research, Education and Practice

Volume 2, Number 1, 2020. 
There are some notable differences between the NXT and EV3 microcontrollers. The NXT cube is controlled by a $48 \mathrm{MHz}$ processor with $64 \mathrm{~K}$ memory while the EV3 cube (see fig. 4.) controls $300 \mathrm{MHz}$ processor with $64 \mathrm{MB}$ of memory. Additionally, when NXT is a cube, the memory space is limited to $256 \mathrm{~KB}$, which may be a big problem for more complex programs. Ev3 microcontroller has an internal memory space much richer + there is a possible extension of memory via USB or SD card to a few GB. The differences between the processors and the memory in these two microcontrollers are reflected in particular in the execution of complex computational operations and the conversion of records per second.

Basic communication on both Lego cubes is via a USB cable that connects directly to the computer in which the program is already ready. The NXT Cube offers more comfort and communication via Bluetooth. The EV3 cube in addition to USB and Bluetooth also offers the ability to control and connectivity via Wifi, which is a great advantage especially for computers that do not have a Bluetooth interface in the base construction.

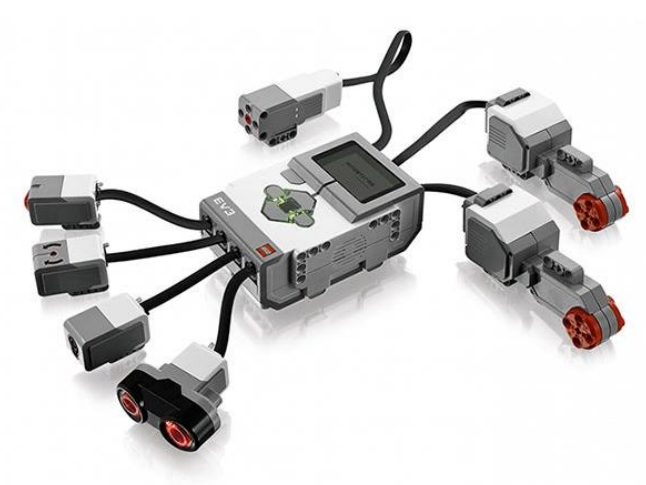

Figure 4: Options for plugging sensors and motors on a microcontroller EV3 [18]

We can programme such smart NXT and EV3 cubes in several ways [9]. The most frequently used are the environment LEGO MINDSTORMS NXT 2.0 and LEGO MINDSTORMS EV3 Home Edition [10], [11], [12]. These two environments are iconic, that is, they are fully graphic and pupils do not need to write long lines of code. They simply store individual graphical blocks of execution in succession and then upload them to the assembled robot. Figure. 5.

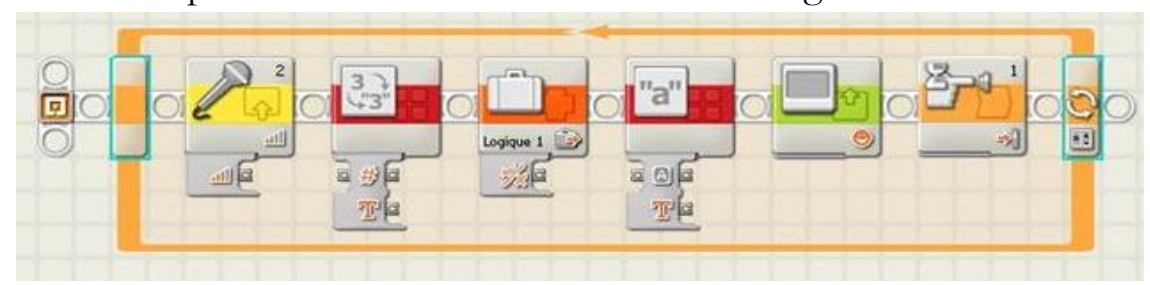

Figure 5: Example of a program in THE NXT-G development environment

In addition to the iconic or graphic programming of robots, there is also the possibility to program the robot directly on a brief microcontroller or programmed in a BricX environment [13], [14], [15]. In the BricX environment, you can write long lines of code and over the icon programming here, students have the opportunity to create a more sophisticated and accurate program. The EV3 cube also supports a higher $\mathrm{C}$ programming language and can therefore compile the code in any $\mathrm{C}$ compiler.

The basic use of Lego Mindstorms is mainly in teaching. In the course of lessons measured for programming and robotics, these kits can be use in particular as a means by which pupils are actually physically familiar with the possibility of programming robots. In the teaching hours, pupils

Central-European Journal of New Technologies in Research, Education and Practice

Volume 2, Number 1, 2020. 
first become acquainted with the hardware of the robots and then with individual development environments also. Subsequently, students can start working on the robot's own project and program various tasks and functions. Students so of course can take advantage of their imagination as a result of the various interesting projects you see. Figure. 6 .

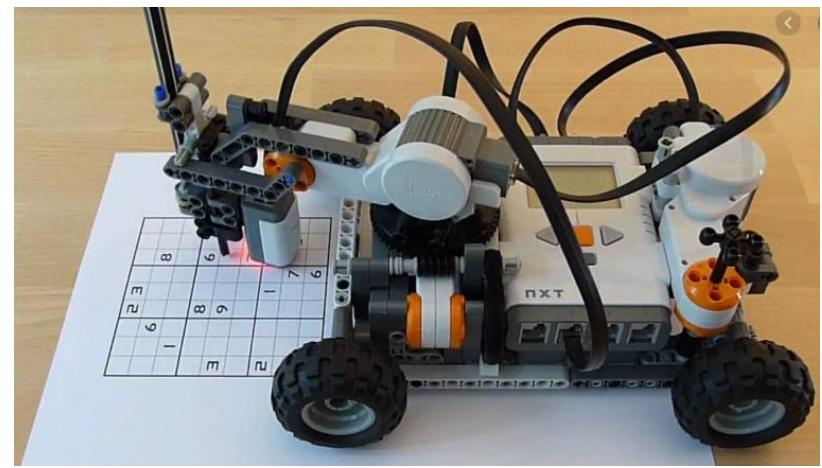

Figure 6: NXT Robot enabling the evaluation and registration of SUDOKU [19]

In addition to the classic lessons, such a kit can be use for other forms of teaching or events also. The University of the Catholic University of Ružomberok is organized annually by the Children's College, which is dedicated to kids from 7 to 12 years, where the workshops from informatics are presented with such Lego Mindstorms. Figure. 7. The children can be familiar with the robot for the first time and have the ability to program them directly on a microcontroller's cube, where they try to work with sound, ultrasonical (ultrasonic) and light sensors. Working with the pupil's bots is very interested in gaining new knowledge and skills from this area. In the children's University was organized a workshop from informatics, which lasted two lessons. In this time, we have been able to present a colleague with colleagues, and what it consists of. The beginning of this workshop was developed in the spirit of the representation of individual pupils. In this section, the pupils gave us their names, where they are, their hobbies and whether they have been met from robotics [16]. Most of these children have already met from robotics just at the workshop, which took place in the previous year. We also introduced the EV3 and NXT cubes and presented a detailed description of what they are composed of. Students could see the wiring of the sensors and the engines also. Then we divided the pupils into groups of three and each group gave a pre-prepared robot, which was constructed according to the basic NXT manual. Pupils gradually programmed this robot directly on a microcontroller's cube. In this part of the lesson pupils programmed the robot a total of 4 times. The programmes were mainly related to the programming of sensors namely touch, ultrasonic, light and acoustic. After this activity, we have finally demonstrated a demonstration of more complex robots to see what all the pupils can build and program through this Lego Mindstorms kit.

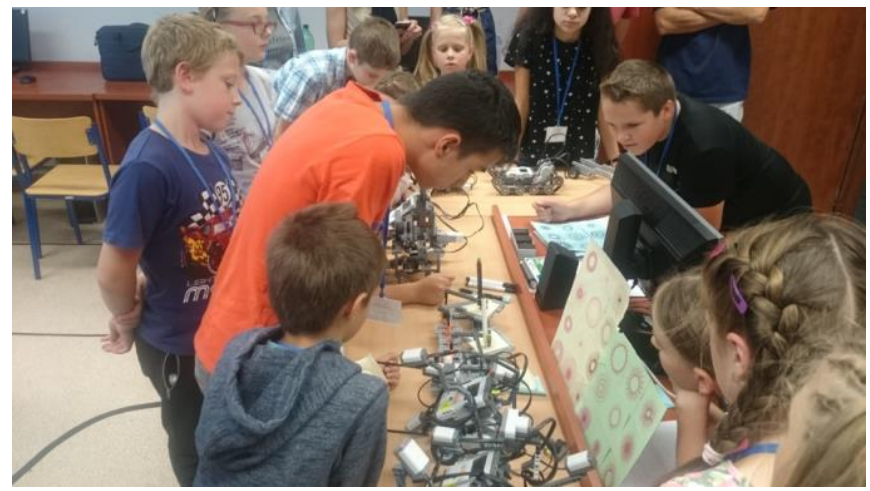

Figure 7: photograph of pupils at the workshop from the Catholic University in Ružomberok

Central-European Journal of New Technologies in Research, Education and Practice

Volume 2, Number 1, 2020. 
We start working on lessons with our teaching science students by explaining the details of what is robotics and cybernetics. We also introduce well-known companies dealing with this issue. Among the most popular company includes Boston Dynamics. This company has seen great advances over the past year in the field of robotics. We divided the students into groups and each of the groups chose one robot to be present for the next hour. After these presentations, we joined the hardware and software, which has the Lego Mindstorms kit. We have described a specific processor, memory, connectivity and compatibility options. We have mentioned what different types of cube can be programmed. In the next part, students build a basic robot according to NXT instructions and try how to program the robot directly on a microcontroller's cube. After these activities, students already know what a NXT robot is and how to program it at a glance and what part is folded.

The next lesson is followed by programming in the environment of Lego Mindstorms NXT 2.0 G and also programming in the Advanced online website makecod.mindstorms.com [14]. Within these two environments, pupils will meet from a more complex programming, which cannot be achieved by programming on a microcontroller cube. The page makecode.com [14] is a wide variety of programming options for a newer EV3 cube with a wide range of tutorials. The student may display a blockprogramming environment similar to the child's Scratch programming language, but can also convert it to a Java code that the cube EV3 understands. The students are ready to create their own project after analyzing the specific environment. This project is characterised by the fact that the students in pairs will build their own robot according to their own status and create a separate code for it. They will use all of their previous knowledge in this way, resulting in interesting projects presented either in the trial or in the end of the teaching unit [13], [16].

\section{Conclusion}

From practical experience, it can be noted that the technology presented to students is very motivable, as they open up the well-known perspective of materializing their ideas by means of 3D printing, the development of motor skills and Technical-Informative thinking using Lego Mindstorms, and both gives a space of creativity and imagination. After all, what is more motivating for man than self-realization and the subsequent award?

\section{References}

1. REPRAP.ORG - RepRapWiki [online] reprap.org/wiki/Main_Page .

2. HUMMING, M. 3d Printer RepRap: Open-source lubricants that make your life easier. Linuxexpres, 2012-09-10 [online] www.linuxexpres.cz/hardware/3d-tisk.

3. TINKERCAD - From mind to design in minutes [online] www.tinkercad.com .

4. FREECAD - Your Own 3D Parametric Modeler [online] www.freecadweb.org .

5. BLENDER - Open Source 3D creation. Free to use for any purpose, forever [online] www.blender.org .

6. GIBB, A - Building Open Source Hardware: DIY Manufacturing for Hackers and Makers, Addison-Wesley: New York, pp. 253-277 (2015).

7. Robotics in informal teaching of informatics. DidInfo 2019, 03.04.2019-05.04.2019, Slovakia, Didinfo 2019: International Conference on Computer Science teaching: 25. Annual conference: Matej Bel University in Banská Bystrica, 2019. ISBN (online) 978-80-557-1533-9. -ISSN (online) 2454-051X, p. 77-81. - io.fpv.umb.sk/didinfo/Zbornik Didinfo 2019.pdf.

Central-European Journal of New Technologies in Research, Education and Practice

Volume 2, Number 1, 2020. 
8. Developing informative thinking through $3 \mathrm{~d}$ press and LEGO robots [electronic document] innovative trends in trade didacties linking theory and Practice teaching strategies to critical and creative thinking, date, Slovak/rec. prof. PhDr. Martin Bílek, Ph.D. doc. paeddr. Juraj chamber, PhD, Nitra (Slovakia): University of Constanina philosopher in Nitra, 2019. -ISBN (online) 978-80-558-1408-7. www.pf.ukf.sk/images/docs/projekty/2017/pCCp/konferencie/2019/APVV\%20Zborn\%C3\%ADk\%202019.pdf.

9. WIKI. ROBOTIKA.SK-building LEGO mindstorm NXT in the classroom [online] wiki.robotika.sk/robowiki/index.php?title=Stavebnice LEGO MINDSTORMS NXT vo vyu $\% \mathrm{C} 4 \% 8$ Dovan $\% \mathrm{C} 3 \% \mathrm{AD}$.

10. EDUCATION. LEGO.COM - MINDSTORMS SOFTWARE [online] education.lego.com/en-us/downloads/mindstorms-ev3/software.

11. HAVELKA, M. . - STOFFOVÁ, V.: Robotika - Stavba a programování robotů (LEGO Mindstorms NXT a EV3) 1. vyd. Olomouc: Pedgogická fakulta UP v Olomouci, 2017. 85. s

12. STOFFOVÁ, V.-.HAVELKA, M.: Práca s robotickými stavebnicami na 2. stupni ZŠ - Zbierka riešených úloh. 1. vyd. Olomouc : Pedgogická fakulta UP v Olomouci, 2018. 66. s.

13. STOFFOVÁ, V. - TAKÁČ, O.: Robotické stavebnice v príprave učitelov informačnej výchovy (Robot kits in teachers preparation for information education). In Havelka, M., Chráska, M., Klement, M., Serafín, Č. (ed.): Trendy ve vædęláváni 2013. Olomouc : agentura GEVAK s.r.o., 2013. 315-322. s. ISBN 978-80-86768-52-6 / ISSN 1805-8949

14. Microsoft.com-Lego Mindstorms Education EV3 [online] makecode.mindstorms.com.

15. SOURCEFORGE.NET - Bricx Command Center [online]

16. STOFFOVÁ, V. - ZBORAN, M.: Hravá forma stavby a programovania robotov na základnej škole. In: Trendy ve vadèlávání, 11, 2018, č. 2, s. 130 - 139. ISSN 1805-8949

17. Figure 3 https://docplayer.nl/docs-images/70/63006544/images/16-2.jpg

18. Figure 4 https://a.allegroimg.com/s1440/035a32/ab060569413584c4506ecf66230a

19. Figure 6 https://miro.medium.com/max/2000/0*ZzhYR2ZYQKri27Kz

\section{Authors}

\section{Igor ČERNÁK}

Catholic University in Ružomberok, Faculty of Education, Slovakia, e-mail: igor.cernak@ku.sk

\section{Michal ROJČEK}

Catholic University in Ružomberok, Faculty of Education, Slovakia, e-mail: michal.rojcek@ku.sk

\section{Patrik SITIARIK}

Catholic University in Ružomberok, Faculty of Education, Slovakia, e-mail: patrik.sitiarik@ku.sk

\section{About this document}

Published in:

CENTRAL-EUROPEAN JOURNAL OF NEW TECHNOLOGIES IN RESEARCH, EDUCATION AND PRACTICE

Volume 2, Number 1. 2020.

ISSN: 2676-9425 (online)

DOI:

10.36427/CEJNTREP.2.1.416

Central-European Journal of New Technologies in Research, Education and Practice

Volume 2, Number 1, 2020. 


\section{License}

Copyright (C ČERNÁK Igor, ROJČEK Michal, SITIARIK Patrik. 2020.

Licensee CENTRAL-EUROPEAN JOURNAL OF NEW TECHNOLOGIES IN RESEARCH, EDUCATION AND PRACTICE, Hungary. This article is an open access article distributed under the terms and conditions of the Creative Commons Attribution (CC-BY) license.

http://creativecommons.org/licenses/by/4.0/

Central-European Journal of New Technologies in Research, Education and Practice

Volume 2, Number 1, 2020. 